\title{
The influence of one memory retrieval on a subsequent memory retrieval ${ }^{*}$
}

\author{
GEOFFREY R. LOFTUS and ELIZABETH F. LOFTUS \\ University of Washington, Seattle, Washington 98195
}

\begin{abstract}
Ss produced an instance of a category and following zero or two intervening items produced a second instance of the same category. The second instance was produced more quickly than the initial instance. This finding, in conjunction with other data reported in the paper, indicate that the reduction in latency for the second instance is due mostly to a reduction in the rate with which the category is searched.
\end{abstract}

In an experiment by Freedman and Loftus (1971), Ss were shown a noun category plus a restricting letter or adjective and were asked to name an instance of the category which began with the letter or which was characterized by the adjective. Reaction time to produce the response was measured. The data were discussed in terms of a model that postulated a hierarchical memory composed of noun categories (e.g., animals) with subsets (e.g., birds, dogs) and supersets (e.g., living things) of each category. Retrieval from this hierarchical structure was assumed to consist of at least two major steps: (1) entering the appropriate category and (2) searching the category for an appropriate member. The times to execute Step 1 and Step 2 are hereafter denoted $t_{1}$ and $t_{2}$, respectively. The duration of $t_{1}$ was estimated to be about $.25 \mathrm{sec}$ by the following reasoning. Ss saw stimuli presented with the category either first (e.g., fruit-P) or second (e.g., P-fruit) and with at least a $1 / 2$-sec interval between the noun and restrictor. Reaction times were measured from the presentation of the second member of the pair. When the category came second, the total retrieval process began only after its presentation and included both $t_{1}$ and $t_{2}$, according to the model. When the category came first, however, $t_{1}$ could be completed before the restrictor was shown. For example, given the stimulus fruit-P, the S could enter the category "fruits" during the interval. Since measured reaction time begins when "P" is presented, measured reaction time excludes $t_{1}$ in this case. The decrease in reaction time when the category is shown first vs second can therefore be equated with $t_{1}$, which is excluded in the former case and included in the latter.

More recently, Loftus (1973) asked Ss to produce a member of a category and a short time later asked them to produce a different member of that category. This was accomplished by showing a category-letter pair (e.g., fruit-P), which asked the $S$ for an appropriate instance,

*Requests for reprints may be sent to either Loftus, Department of Psychology, University of Washington, Seattle Washington 98195. The research was supported by a National Institute of Mental Health grant to $E$. Loftus and a Nationa Science Foundation grant to $G$. Loftus. Appreciation is expressed to Thomas $O$. Nelson for his comments on the manuscript. then, following zero, one, or two intervening items, showing the same category paired with a different letter (e.g., fruit-A), which asked for a different instance. Interest centered around the question of whether the speed of retrieving the second instance of a category was affected by the retrieval of the first instance and/or the lag between the two retrievals. The results indicated that response latency for the second instance was shorter than response latency for the first instance and increased monotonically with the number of intervening items. For example, a $S$ 's baseline time to name a fruit beginning with the letter "P" was $1.52 \mathrm{sec}$. However, it took him $1.22 \mathrm{sec}$ to produce the same response if he had named a different fruit on the previous trial and $1.29 \mathrm{sec}$ to produce the response if he had named a different fruit two trials back.

The results of the Loftus (1973) study thus indicate that the process of retrieving information from a category facilitates a subsequent retrieval from that category. However, in this experiment the $S$ was presented with the category name and restricting letter simultaneously; retrieval time thus included both $t_{1}$ and $t_{2}$. Consequently, the facilitation effect could have involved a reduction in $t_{1}$ or $t_{2}$ or both. The present experiment is designed to distinguish among these three possibilities.

In some conditions of the present experiment, an interval was inserted between the category name and the letter and the stimuli were presented either in the order category-letter or in the order letter-category [as in the Freedman \& Loftus (1971) study]. As noted above, this procedure allows an estimation of $t_{1}$. Additionally in the present experiment, the $S$ was required to name an instance of a category and shortly thereafter was asked to name a second instance of the category [as in the Loftus (1973) study]. This design is sufficient to determine the locus of the reduction in reaction time to name a second category instance.

Figure 1 shows three possible patterns of results. Suppose first that only category entry time, $t_{1}$, is reduced when a second category instance is produced. In this case, the results shown in Fig. 1a should obtain: the 


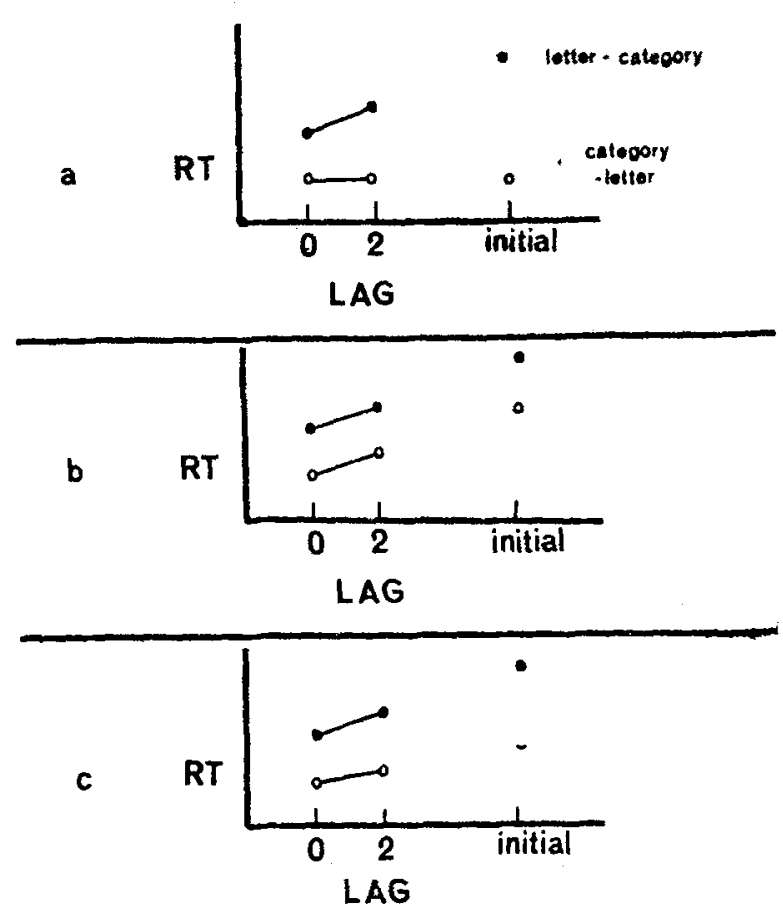

Fig. 1. Three possible patterns of results for the relationship between time and the number of intervening items (lag) between two appearances of a critical category.

letter-category conditions (which include $t_{1}$ ) should depend on the prior retrieval, whereas the category-letter conditions (which exclude $t_{1}$ ) should not.

Conversely, suppose that only category search time, $t_{2}$, is reduced when the second category instance is produced. Such a situation would lead to the results shown in Fig. 1b. Both the category-letter and the letter-category conditions include $t_{2}$, so they should be affected equally by the initial retrieval.

The final possibility is that both $t_{1}$ and $t_{2}$ are reduced. This situation would predict the results shown in Fig. 1c. Here, the category-letter condition (which includes $t_{2}$ but not $t_{1}$ ) should be affected by the initial retrieval, but the letter-category condition (which includes both $t_{1}$ and $t_{2}$ ) should be affected to a greater degree.

\section{METHOD}

\section{Subjects}

Eighteen Ss from the New School for Social Research received $\$ 5$ for their participation in two 1-h sessions, which occurred on 2 consecutive days. No $S$ had previously participated in a memory experiment.

\section{Materials}

Each stimulus was printed in block letters on a $5 \times 8$ in. index card. A stimulus always consisted of a category name plus a letter (e.g., fruit-P). Eighty critical category names were selected from the Battig and Montague (1969) and Shapiro and Palermo (1970) category norms. Each of the category names was paired with two different letters. If "dominance" is defined as the frequency with which a word is given as an exemplar of a category, then one of the two category-letter stimuli will be referred to as more dominant than the other.

In addition to the 160 critical stimuli (80 categories each paired with two letters), 80 filler stimuli were used. The filler stimuli also consisted of a category plus a letter. Some of the filler categories were used only once; others appeared twice with two different letters. Thus, each S saw 240 unique stimuli ( 80 critical categories, each paired with two letters, plus 80 filler stimuli).

\section{Design}

There were three within-S factors: order (category-letter vs letter-category), interval (simultaneous presentation of the stimuli vs 2.5 -sec interval between the category name and the letter), and $\operatorname{lag}(\operatorname{Lag} 0, \operatorname{Lag} 2$, and initial presentation). These factors were combined factorially, thereby giving a 2 (orders) by 2 (intervals) by 3 (lags) by 18 (Ss) design.

Each $\mathrm{S}$ received a different permutation of the 240 items with the following restrictions:

(1) The initial presentation of a critical category-letter pair was followed after zero or two intervening filler items (i.e., at Lag 0 or at Lag 2) by the presentation of the same category paired with a different letter. Each $S$ received 40 stimuli presented at Lag 0 and 40 at Lag 2.

(2) On half of the trials, Ss saw the stimulus corresponding to the high dominant instance before seeing the stimulus corresponding to the low dominant instance. For the remaining trials, the reverse arrangement held. A given category was presented in the order dominant-nondominant for half the Ss and in the reverse order for the remaining half of the Ss.

\section{Procedure}

Each S was told that he would see items consisting of categories and letters and that he was to respond with a word in the category that began with the given letter. He was given examples and told to respond as quickly as possible, but to avoid errors.

The $S$ sat in front of a screen with a window covered by half-silvered glass. An index card containing the stimulus was placed in a dark enclosure behind the mirror and was presented by illuminating the enclosure. A microphone was placed in front of the $S$, and he responded by speaking into it.

A trial consisted of the following: (a) a card with the item printed in large type was placed in the darkened enclosure; (b) the E said "ready" and pressed a button which illuminated the first member of the stimulus pair; (c) either simultaneously or after a 2.5-sec interval, the second member of the pair was automatically illuminated and an electric timer started; (d) the $S$ 's verbal response activated a voice key that stopped the timer and terminated the trial. A warm-up period of 20 trials preceded the experimental trials each day.

\section{RESULTS}

Only correct responses $(96 \%)$ to the critical stimuli were included in the following analyses. Median latencies were obtained for each S's responses in each of the 12 conditions. For each condition, mean latencies were then obtained by averaging the medians from individual Ss; these means are plotted in Figs. 2 and 3. Figure 2 shows the results when the 2.5 -sec interval was inserted between the category and the letter. In both the letter-category and category-letter conditions, a second instance of a category is produced faster than the first instance; furthermore, a second instance is produced faster at Lag 0 than at Lag 2. Figure 3 indicates that the same pattern of results obtains when letter and noun are presented simultaneously.

A 2 (orders) by 2 (intervals) by 3 (lags) analysis of variance was done on the latency data. Significant effects were found for $\operatorname{lag}[F(2,34)=6.57, \mathrm{p}<.05]$, 
category-letter order $[F(1,17)=14.71, p<.01]$, and interval $[F(1,17)=33.52, p<.01]$. None of the two-way or three-way interactions was significant $(\mathrm{F}<1$ for all cases).

\section{DISCUSSION}

\section{Dependence of Memory Retrievals}

A number of studies have indicated that the time to retrieve information from a semantic category is decreased if that category has been accessed a short time previously. Collins and Quillian (1970), for example, have shown that the time required to answer such questions as "Is a canary a bird?" is decreased by as much as $600 \mathrm{msec}$ if information about canaries has been accessed on the previous trial. Using a somewhat different paradigm, Meyer and Schvaneveldt (Meyer \& Schvaneveldt, 1971; Meyer, Schvaneveldt, \& Ruddy, 1972; Schvaneveldt \& Meyer, 1973; Meyer, 1973) have shown the same thing. In these experiments, Ss were required to classify letter strings as words or nonwords. The general finding was that the reaction time to classify a letter string as a word is faster if the $S$ has just classified a semantically similar word as opposed to a semantically dissimilar word. Thus, for example, the time it takes to classify "butter" as a word is faster if "butter" is preceded by "bread" than if it is preceded by "nurse."

Two general classes of models have been proposed to handle such results. A location shifting model (Meyer \& Schvaneveldt, 1971) assumes that when a S has finished processing a member of a particular category and must then shift to begin processing a second category, the shift time is dependent upon the semantic distance between the two categories. An activation model, on the other hand, assumes that when items in a category are processed, other items are "excited" or "activated" to the extent that they are semantically similar to the information being processed. Two further assumptions are made: first (Warren, 1970) that activation decays

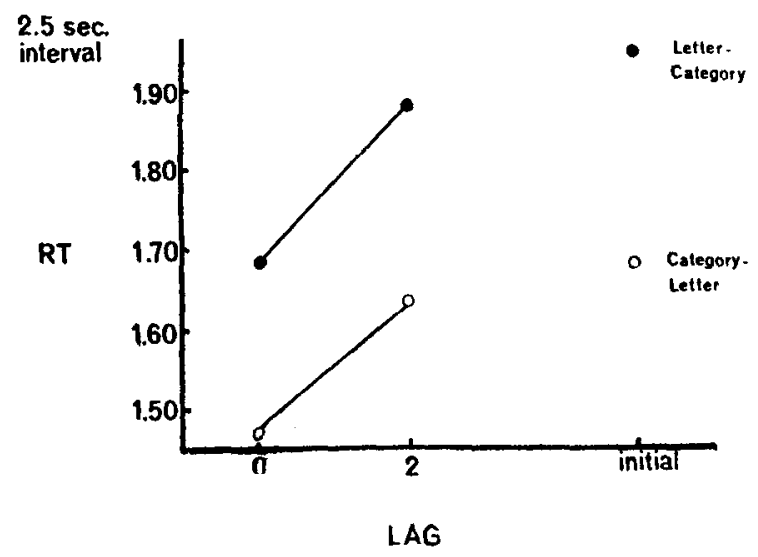

Fig. 2. Mean reaction time in seconds as a function of the number of intervening items (lag) between two appearances of a critical category. Items were presented with a $2.5-\mathrm{sec}$ interval between the category and the letter.

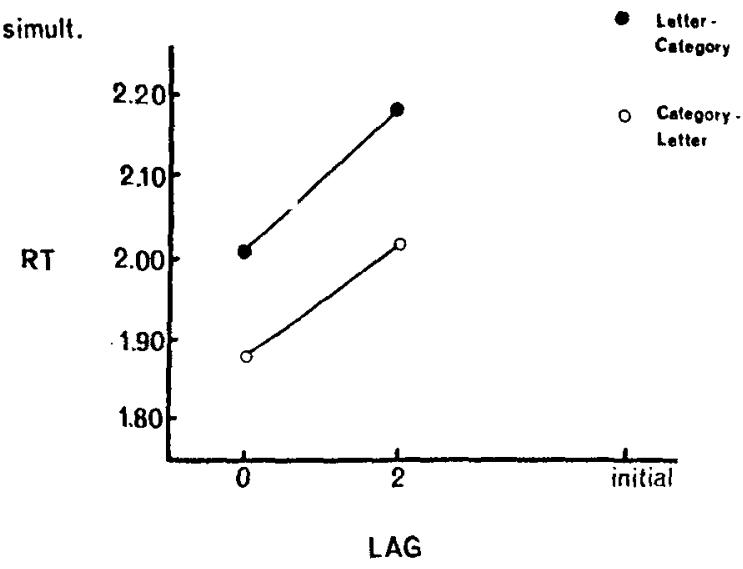

Fig. 3. Mean reaction time in seconds as a function of the number of intervening items (lag) between two appearances of a critical category. The category and letter were presented simultaneously.

away over time and second that activated items are more readily accessible than nonactivated items.

The results of the present experiment together with the data of Meyer et al (1972) and Loftus (1973) disconfirm the location shifting model and support the activation model. All of these experiments involve the following sorts of comparisons. Let $\mathrm{T}$ represent target information whose time to be processed is the dependent variable of interest. Let $R$ represent information which is semantically related to $T$, and finally let $U_{1}$ and $U_{2}$ represent information which is semantically unrelated to $T$. Now consider three conditions:

Condition a: Process $\mathrm{U}_{1} ;$ Process $\mathrm{U}_{2} ;$ Process $\mathrm{T}$.

Condition b: Process R; Process $\mathrm{U}_{2}$; Process $\mathrm{T}$.

Condition c: Process $\mathrm{U}_{1}$; Process R; Process T.

The data show that $T$ is processed fastest in Condition c, next fastest in Condition b, and slowest in Condition a. Both the location shifting model and the activation model correctly predict that reaction time in Condition $c$ would be faster than reaction time in Conditions a and $b$. However, the predictions of the two models differ with regard to the relationship between Conditions $a$ and $b$. A location shifting model incorrectly predicts that reaction time would be the same for Conditions a and $b$, since in both cases the $S$ is shifting from the unrelated category, $\mathrm{U}_{2}$ to $\mathrm{T}$. An activation model, on the other hand, correctly predicts the obtained pattern of results. This is because in Condition $\mathrm{b}, \mathrm{T}$ is assumed to have been activated by $\mathrm{R}$, and this activation has not decayed by the time $T$ is processed. In Condition a, on the other hand, $T$ is not assumed to have been activated at all; therefore, time to process $T$ would be longer.

\section{Processing Stages}

In the outset of this report, it was noted that the semantic retrieval model proposed by Freedman and 
Table 1

Time Estimates (in Seconds) for Memory Retrieval Stages as a Function of Three Lag Conditions

\begin{tabular}{llccc} 
& & \multicolumn{3}{c}{ Lag Condition } \\
\cline { 3 - 5 } & Retrieval Stage & Lag 0 & Lag 2 & Initial \\
\hline $\mathrm{t}_{1}$ & Category entry time & 0.20 & 0.22 & 0.27 \\
$\mathrm{t}_{2}+\mathrm{k}$ & $\begin{array}{l}\text { Category search } \\
\text { time plus baseline }\end{array}$ & 1.47 & 1.65 & 1.69 \\
$\mathrm{t}_{3}$ & Eye movement time & 0.14 & 0.14 & 0.13 \\
$\mathrm{t}_{4}$ & Extra encoding time & 0.21 & 0.16 & 0.22 \\
\hline
\end{tabular}

Loftus (1971) postulates two major processing stages: entering a category (which takes time $t_{1}$ ) and searching the category (which takes time $t_{2}$ ). Another stage, taking time $\mathrm{k}$, is a baseline stage, involving response execution, etc. Unfortunately, these stages are not sufficient to handle the data from the present experiment. To see why this is so, consider the reaction times to initially access a category. These reaction times fall into a 2 by 2 design with order (category-letter vs letter-category) and interval ( $2.5 \mathrm{sec}$ vs simultaneous) as factors. According to the Freedman-Loftus model, the processing times involved in initial access should be as follows:

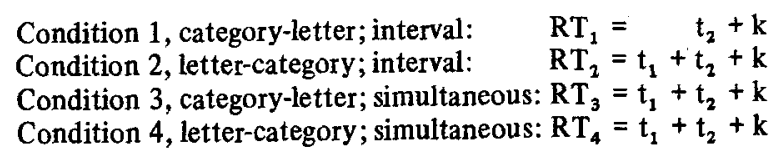

Thus reaction times for Conditions $2-4$ should be equal to each other and should differ (by $t_{1}$ ) from the reaction time to Condition 1. However, the data indicate that all four reaction times differ from one another, thereby necessitating the postulation of additional processing stages. First, in Condition 4, the predisposition to encode the category before the letter may conflict with normal left-to-right reading habits. Thus, an additional eye fixation could sometimes occur in Condition 4 relative to the other three conditions. We shall label the time for this additional eye fixation $t_{3}$. Secondly, when category and letter are presented simultaneously (Conditions 3 and 4), reaction time must include the time to encode both stimuli. With a 2.5 -sec interval, on the other hand (Conditions 1 and 2), reaction time includes the time to encode only one of the two stimuli. Let the extra encoding time required in Conditions 3 and 4 be designated by $t_{4}$.

We are now in a position to include the two new stages in the four initial reaction times.

(1a) Category-letter; interval:

$$
\mathrm{RT}_{1}=\mathrm{t}_{2} \quad+\mathrm{k}=1.69 \mathrm{sec}
$$

(1b) Letter-category; interval:

$$
\mathrm{RT}_{2}=\mathrm{t}_{1}+\mathrm{t}_{2} \quad+\mathrm{k}=1.96 \mathrm{sec}
$$

(1c) Category-letter; simultaneous:

$$
\mathrm{RT}_{3}=\mathrm{t}_{1}+\mathrm{t}_{2}+\mathrm{t}_{4}+\mathrm{k}=2.18 \mathrm{sec}
$$

(1d) Letter-category; simultaneous:

$$
\mathrm{RT}_{4}=\mathrm{t}_{1}+\mathrm{t}_{2}+\mathrm{t}_{3}+\mathrm{t}_{4}+\mathrm{k}=2.31 \mathrm{sec}
$$

By appropriate manipulations of Eqs. 1a-4a, we find that $\mathrm{t}_{1}=0.27 \mathrm{sec}\left(\mathrm{RT}_{2}-\mathrm{RT}_{1}\right) ;\left(\mathrm{t}_{2}+\mathrm{k}\right)=1.69 \mathrm{sec}$ $\left(\mathrm{RT}_{1}\right) ; \mathrm{t}_{3}=0.13 \mathrm{sec}\left(\mathrm{RT}_{4}-\mathrm{RT}_{3}\right) ;$ and $\mathrm{t}_{4}=0.22 \mathrm{sec}$ $\left(\mathrm{RT}_{3}-\mathrm{RT}_{2}\right.$ ). The estimate of $0.27 \mathrm{sec}$ for $\mathrm{t}_{1}$ (category entry time) coincides well with previous estimates obtained by Freedman and Loftus (1971) and Loftus and Freedman (1972). The estimate of $0.22 \mathrm{sec}$ for $t_{4}$ (encoding time) is far greater than one would expect if "encoding" meant only the process of pattern-recognizing the visual stimulus (cf. Sperling, 1963, who estimated $10 \mathrm{msec}$ per item for the pattern-recognition process). Thus the obtained estimate of $0.22 \mathrm{sec}$ must include a great deal more processing, although it is impossible in the present experiment to determine what such encoding might consist of. Finally, since an eye fixation usually lasts on the order of $200-300 \mathrm{msec}$, the estimate of $0.13 \mathrm{sec}$ for $t_{3}$ (extra fixation time) is somewhat less than one would expect. A possible reason for this discrepancy is that additional eye fixations may not be made on all of the Condition 4 trials. The notion of an extra eye fixation sometimes occurring in Condition 4 is, of course, easily testable.

One more parenthetical remark should be made. As noted above, the interaction of interval time and category-letter order was not significant. If the null hypothesis of no interaction is accepted, then inspection of Eqs. 1a-4a indicates that $t_{1}=t_{3}$. (This can be seen either by the fact that $\mathrm{RT}_{3}-\mathrm{RT}_{1}=\mathrm{RT}_{4}-\mathrm{RT}_{2}$ or by the fact that $\mathrm{RT}_{2}-\mathrm{RT}_{1}=\mathrm{RT}_{4}-\mathrm{RT}_{3}$, both of which are true under the null hypothesis.) However, since nothing in the present experiment necessarily warrants acceptance of the null hypothesis, the equality of $t_{1}$ and $t_{3}$ should not be taken very seriously.

\section{What Stage Does Activation Affect?}

Using the logic outlined above, it is possible to obtain estimates of $t_{1},\left(t_{2}+k\right), t_{3}$, and $t_{4}$ for second category presentations at Lags 0 and 2 . These estimates, along with the estimates given above for initial presentation, are shown in Table 1. The statistical analyses of the data indicate that the only parameter which reliably changes over lag condition is $t_{2}+k$. If we make the reasonable assumption that $\mathrm{k}$ remains constant over lag conditions, then $t_{2}$, the category search time, constitutes the locus of the activation effect. This finding agrees with the conclusion of Meyer (1973, p. 30), who noted that "The semantic distance between categories ... may affect the search rate for the second category."

The invariance of encoding time $\left(t_{4}\right)$ over lag condition is somewhat at odds with the finding of Meyer et al (1972, Experiment 3) that encoding time appears to be shortened by prior processing of semantically similar information. The reason for this discrepancy is not entirely clear. A possible explanation may lie in the fact that the processing delay between the two categories was much shorter in the Meyer et al experiment than in the present experiment, and the activation decay function for encoding time may be 
different from the analogous decay function for search rate.

\section{REFERENCES}

Battig, W. F., \& Montague, W. E. Category norms for verbal items in 56 categories: A replication and extension of the Connecticut category norms, Journal of Experimental Psychology Monograph, 1969, 80(3, Pt. 2).

Collins, A. M., \& Quillian, M. R. Facilitating retrieval from semantic memory: The effect of repeating part of an inference. In A. F. Sanders (Ed.), Attention and performance III. Amsterdam: North-Holland, 1970.

Freedman, J. L., \& Loftus, E. F. Retrieval of words from long-term memory. Journal of Verbal Learning \& Verbal Behavior, 1971, 10, 107-115.

Loftus, E. F. Activation of semantic memory. American Journal of Psychology, 1974, in press.

Loftus, E. F., \& Freedman, J. L. Effect of category-name frequency on the speed of naming an instance of the category. Journal of Verbal Learning \& Verbal Behavior, 1972, 11, 343-347.

Meyer, D. E. Correlated operations in searching stored semantic categories. Journal of Experimental Psychology, 1973, 99, 124-133.

Meyer, D. E., \& Schvaneveldt, R. W. Facilitation in recognizing pairs of words: Evidence of a dependence between retrieval operations. Journal of Experimental Psychology, 1971, 90, 227-234.

Meyer, D. E., Schvaneveldt, R. W., \& Ruddy, M. G. Activation of lexical memory. Paper presented at the meeting of the Psychonomic Society, St. Louis, November 1972.

Schvaneveldt, R. W., \& Meyer, D. E. Retrieval and comparison processes in semantic memory. In S. Kornblum (Ed.) Attention and performance IV. New York: Academic Press, 1973.

Shapiro, S. I., \& Palermo, D. S. Conceptual organization and class membership: Normative data for representatives of 100 categories. Psychonomic Monograph Supplements, 1970 $3(11$, Whole No. 43).

Sperting, G. A model for visual memory tasks. Human Factors, $1963,5,19-31$.

Warren, R. E, Stimulus encoding and memory. Unpublished loctoral dissertation, University of Oregon, 1970.

(Received for publication September 17, 1973; revision accep ted December 6, 1973.) 